\title{
A PREVALÊNCIA DAS DOENÇAS EM PACIENTES QUE REALIZAM FISIOTERAPIA HOSPITALAR
}

\author{
Alexsandra Marinho Dias ${ }^{1}$ \\ Daniela Albano ${ }^{2}$ \\ Morgana Araújo da Silva ${ }^{3}$ \\ Fabiola Hermes Chesani ${ }^{4}$ \\ Rubia Mara Giachini Kesler ${ }^{5}$ \\ Emmanuel Alvarenga Panizzi ${ }^{6}$ \\ Edilaine Kerkoski ${ }^{7}$
}

Resumo: Atualmente existem poucos estudos sobre a prevalência das doenças de pessoas internadas que realizam fisioterapia hospitalar, frente a esta carência o estudo teve como objetivo verificar a prevalência das principais doenças que levaram ao atendimento fisioterapêutico num hospital público da região do Vale do Itajaí. Para esta análise foram utilizados como instrumento as tabelas de registro de atendimentos fisioterapêuticos realizados nos setores de clínica médica, clínica cirúrgica, clínica pediátrica e unidade de terapia intensiva (UTI) do hospital público da região do Vale do Itajaí, considerados todos os registros de pacientes atendidos pela Fisioterapia correspondente ao período de fevereiro de 2015 a julho de 2016. Obtivemos como resultado desta pesquisa que a maior parte das patologias atendidas pela fisioterapia no hospital público da região do Vale do Itajaí são de origens pulmonares e ortopédicas e ainda assim se destaca a atuação precoce deste profissional contribuindo para uma redução do tempo médio de permanência no setor e para uma estabilização mais rápida do quadro clínico dos pacientes.

Palavras-chave: Fisioterapia hospitalar; Doenças; Atendimento fisioterapêutico.

\footnotetext{
${ }^{1}$ Curso de Fisioterapia/UNIVALI/Brasil. E-mail: alexsandradias@univali.br.

${ }^{2}$ Curso de Fisioterapia/UNIVALI/Brasil. E-mail: daniella_albano@hotmail.com.

${ }^{3}$ Curso de Fisioterapia/UNIVALI/Brasil. E-mail: morganaaraujo.sam@hotmail.com.

${ }^{4}$ Curso de Fisioterapia/UNIVALI/Brasil. E-mail: fabiola.chesani@univali.br.

${ }^{5}$ Curso de Fisioterapia/UNIVALI/Brasil. E-mail: rubia@univali.br.

${ }^{6}$ Curso de Fisioterapia/UNIVALI/Brasil. E-mail: pannizi@univali.br.

${ }^{7}$ Curso de Fisioterapia/UNIVALI/Brasil. E-mail: kerkoski@univali.br.
} 